\title{
LA LÁMPARA DEL SAGRARIO DE LA IGLESIA DEL SANTO SEPULCRO DE OSUNA: UNA PIEZA EXCEPCIONAL DEL RENACIMIENTO SEVILLANO
}

\author{
THE SACRARIUM LAMP OF THE HOLY SEPULCHRE \\ CHURCH IN OSUNA: A MASTERPIECE \\ OF THE SEVILLIAN RENAISSANCE
}

\author{
Antonio Joaquín Santos Márquez \\ Universidad de Sevilla. España \\ ORCID: 0000-0002-7671-0936 \\ anjo@us.es
}

\begin{abstract}
En este estudio se da a conocer una obra excepcional de la platería renacentista sevillana, la lámpara del sagrario de la iglesia del Santo Sepulcro de Osuna. Una creación que se inserta dentro de la promoción artística llevada a cabo por don Juan Téllez Girón durante la construcción y adorno de este templo y panteón dinástico. Además, en la actualidad es uno de los ejemplares más antiguos conservados dentro de su tipología en la orfebrería sevillana.

Palabras clave: lámpara; platería; renacimiento; Sevilla; Osuna.
\end{abstract}

This paper studies a masterpiece of the Sevillian Renaissance silverware, the sacrarium lamp of the Holy Sepulchre Church in Osuna. This piece is a work promoted by don Juan Téllez in the mid$16^{\text {th }}$ century, when the fourth Count of Ureña raised this temple-pantheon in Osuna. In addition, it is one of the oldest works within its typology.

Keywords: lamp; silverwork; Renaissance; Seville; Osuna.

La iglesia del Santo Sepulcro de Osuna es uno de los recintos más ricos y uniformes del renacimiento sevillano. Construida bajo la cabecera de la colegiata de Osuna, fue el resultado del deseo de don Juan Téllez Girón de singularizar con un culto propio a su panteón familiar. Una fundación erigida gracias a una bula papal otorgada al IV conde de Ureña por Paulo III el 26 de febrero de 1545, en la que se le concedía la facultad de construir este templo personal con derecho de enterramiento, incorporado a la capilla de San Andrés de Roma, y asistido por 
nueve capellanes perpetuos que formarían cabildo semejante al de su colegiata ursaonense ${ }^{1}$. La fundación preveía también la institución de un clérigo beneficiado y dos clérigos muchachos, además de dos sacristanes, tres acólitos, un organista y una capilla musical ${ }^{2}$. Asimismo, tal y como deseaba el propio conde, sus nueve capellanes podían reservar el Santísimo Sacramento de la Eucaristía, hacer monumento, celebrar oficios divinos de día y de noche, y tener estatutos propios bajo la autorización del conde. Para su mantenimiento, dotó a este templo con 150.000 maravedíes de renta anual que se cargaban sobre unos inmuebles ecijanos, concediéndole el mismo papa, por un decreto dado el 22 de julio de 1555, la prerrogativa de poder ser el patrono quien eligiese al capellán mayor del capítulo del Santo Sepulcro, pues en principio debía ser obligatoriamente un canónigo de la colegiata. Precisamente en este año se terminaban las obras y se constituía definitivamente la fundación, con la redacción de sus estatutos y su aprobación en el primer cabildo de sus capellanes presidido por el conde y celebrado el 5 de diciembre ${ }^{3}$.

Por lo tanto, entre 1545 y 1555 se construyó todo el recinto y se adornó con numerosos bienes muebles, los cuales, en su mayoría, procedían de los obradores sevillanos de esos años. Y, de hecho, la arquitectura de su iglesia de tres naves, capilla sacramental, sacristía y claustro con dependencias para el referido clero, son un claro ejemplo del plateresco sevillano y donde, a pesar de su anonimato, se ha visto la traza y el ingenio del arquitecto Martín de Gainza ${ }^{4}$. Más información documental tenemos de sus retablos, esculturas y pinturas, obras en su mayoría realizadas por artistas de la Sevilla de mediados del quinientos como Guillén Ferrant, Roque Balduque, Bartolomé de Ortega y Hernando de Esturmio, e incluso otras importadas de tierras lejanas como la pintura de Gerard Witwel de Utrecht $^{5}$. Pero igualmente el conde de Ureña dotó a esta iglesia de un importante conjunto de ornamentos, entre los que sobresalían los "veinticinco ternos completos de terciopelo de brocado de oro y plata, bordado con gran número de imagine-

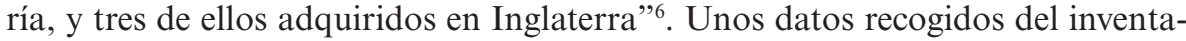
rio póstumo de don Juan que hace su hijo don Pedro Téllez Girón, primer duque de Osuna, en 1559, y que también nos informa del rico tesoro que el conde donó al templo y en el que destacaban "dos piezas de oro bruñido con algunas perlas y piedras preciosas y la una es un cáliz de oro con su patena y la otra una cruz de

${ }^{1}$ RODRÍGUEZ-BUZÓN CALLE, Manuel: La Colegiata de Osuna. Sevilla, 1982, p. 105.

2 ARIZA Y MONTER-CORACHO, Antonio: Bosquejo biográfico de Don Juan Téllez Girón IV Conde de Ureña. Osuna, 1890, p. 21.

${ }^{3}$ RODRÍGUEZ-BUZÓN CALLE, Manuel: La Colegiata ..., op. cit., pp. 104-105.

${ }^{4}$ Ibidem, p. 104; y MORALES MARTÍNEZ, Alfredo: "Transición y modernidad, 1526-1563”, en Arquitectura del Renacimiento en España 1488-1599. Madrid, 1993, pp. $140-141$

${ }^{5}$ RODRÍGUEZ-BUZÓN CALLE, Manuel: La Colegiata ..., op. cit., pp. 109-112.

${ }^{6}$ Ibidem, pp. 111-112. 
altar con una imagen de un crucifijo de oro bruñido con algunas perlas y piedras preciosas engastadas en la dicha cruz, y asimismo entre otras muchas piezas de plata de servicio de la Santa Capilla yo di unas andas de plata y un cofre de plata para encerrar el SSmo. Sacramento en la semana santa", obra esta última que aún se conserva, realizada por el orfebre sevillano Álvaro Rodríguez ${ }^{7}$. Además, seguidamente se relacionan tres custodias, especificando que una de ellas procedía de Alemania y que claramente se puede identificar con el bellísimo ejemplar de Augsburgo, labrado por Stephan Kipfenberger hacia 1540, y que aún se conserva en el Museo de la Colegiata ${ }^{8}$. El listado de donaciones de plata continúa con un relicario, diez cruces, catorce cálices, siete portapaces, tres pares de vinajeras, cuatro hostiarios, cinco campanillas, tres navetas, una bandeja, dos acetres, cuatro cetros y cinco lámparas?.

Pues bien, de estas últimas dádivas argénteas, también aún hoy se conserva una pieza totalmente inédita, ya que en todos los estudios realizados sobre el patrimonio de este templo nunca se la ha tenido en cuenta, a pesar de ser bastante representativa e importante dentro de la orfebrería de esta misma época ${ }^{10}$. Concretamente hablamos de una lámpara hoy ubicada en la capilla sacramental del recinto, y que sin duda se trata de una de las cinco lámparas mencionadas en el inventario de 1559, y la única conservada según se atestigua en otro inventario posterior fechado en $1861^{11}$. Una obra cuya singularidad radica, no solo en su gran calidad, sino especialmente en ser la única lámpara conservada de la orfebrería plateresca sevillana (Figura 1). De hecho, tan solo se tienen dos ejemplos de lámparas históricas anteriores al siglo XVII, centuria de la que ya se conservan en un número bastante elevado. Concretamente, la más antigua es la lámpara gótica de doña Beatriz de Castilla custodiada en el convento de San Clemente de Sevilla, obra posiblemente ejecutada en 1409 reutilizando elementos más antiguos, y la

7 SANZ SERRANO, María Jesús: Catálogo de orfebrería de la colegiata de Osuna. Sevilla, 1979, pp. 8-10; y CRUZ VALDOVINOS, José Manuel: Cinco siglos de platería sevillana. Sevilla, 1992, pp. 326-327.

${ }^{8}$ De hecho, igualmente en el inventario de 1586 se hace referencia como "custodia de plata labrada en Alemania". Agradezco a Francisco Ledesma la entrega de este documento. AHO (Archivo Histórico de Osuna), Protocolos Notariales de Osuna, leg. 58, escribano Antonio García, 1586-1589, s. f., 13-1-1586. Esta obra ha sido estudiada por SANZ SERRANO, María Jesús: Catálogo de orfebrería..., op. cit., pp. 34-36; y CRUZ VALDOVINOS, José Manuel: Platería europea en España (1300-1700). Madrid, 1997, pp. 137-139.

9 ARIZA Y MONTER-CORACHO, Antonio: Bosquejo biográfico de Don Juan..., op. cit., pp. 23-24.

${ }^{10}$ Sobre la plata de la colegiata donde se incluían las piezas del Santo Sepulcro ver SANZ SERRANO, María Jesús: Catálogo de orfebrería de la colegiata..., op. cit.

11 ARIZA Y MONTER-CORACHO, Antonio: Bosquejo biográfico de Don Juan..., op. cit., pp. 23-25. 
segunda se guarda en la parroquia de San Julián también de la capital y fue donada por el veinticuatro don Diego de Postigo en $1575^{12}$. Por lo tanto, el ejemplar de Osuna sería el eslabón que nos permite conocer la propia evolución de la lámpara votiva sevillana entre el modelo gótico y el manierista, ya que es una creación propia del pleno renacimiento o plateresco sevillano.

Como es habitual en este género de piezas para iluminar, se compone de un plato para el aceite donde ardería la luz, colgado de unas cadenas que a su vez se enganchaban en otro plato, en este caso invertido, que pendía gracias a una argolla del colgador o pescante de hierro ubicado en el muro lateral de la capilla. El plato principal es de planta circular y de paredes convexas, siendo su base plana (Figura 2). Este presenta una orilla saliente y llana, cuya superficie recoge un friso cubierto por un punteado que enmarca un tallo vegetal sinuoso y que genera un luminoso contraste entre el ornamento liso y el fondo picado. La orilla da paso a un voluminoso cuerpo convexo, ocupado por gruesos y salientes ovoides con una incisión vertical central que recuerdan a cascabeles -o a mal llamados granos de café-, los cuales, dispuestos simétricamente y en un número de doce, enmarcan y alternan con finas labores grabadas que recrean grutescos a manera de candelieri. Estos se resuelven a base de unas guirnaldas vegetales con lazadas en su base, donde penden máscaras y panoplias - escudos, espadas, carcajes o arcos entre otros-, y que es un ornamento basado claramente en las estampas circulantes de la época ${ }^{13}$. Tras este cuerpo, una gruesa corona de hojas de laurel de clásica y carnosa apariencia, nuevamente recurrente del ornato antiguo, da paso a la base del plato (Figura 3). Esta está resuelta con una corona de gallones rehundidos dispuestos de manera radial rodeando otra laureola más menuda que acoge las armas de los Téllez Girón. Este escudo está inserto en una tarja con extremos enrollados y presenta los típicos tres cuarteles: el inferior apaisado con los girones propios de los señores de Osuna, y los dos superiores con el castillo y el león rampante. De tres argollas dispuestas simétricamente en la orilla del plato, arrancan las tres cadenas de las que pende la lámpara, las cuales presentan eslabones de la época describiendo ochos con una lazada central en aspa. Sujetas también a tres argollas del colgador, este es muy similar al plato, aunque de un diámetro menor y más vertical. En este caso, comienza en otra orilla saliente, ligeramente convexa y decorada con similares cascabeles algo apuntados entre hojas triangulares de

${ }^{12}$ Sobre la lámpara de San Clemente consultar SANCHO CORBACHO, Antonio: Orfebrería sevillana de los siglos XIV al XVIII. Sevilla, 1970, n² 2; SANZ SERRANO, María Jesús: La orfebrería sevillana del barroco. T. II. Sevilla, 1976, p. 201; y PAREJA LÓPEZ, Enrique: "Obras maestras de arte", en Real Monasterio de San Clemente. Historia, Tradición y Liturgia. Córdoba, 1999, pp. 460-464. Sobre la de San Julián ver SANZ SERRANO, María Jesús: La orfebrería sevillana..., T. II, op. cit., p. 228.

13 FERNÁNDEZ ARENAS, José: "La decoración grutesca. Análisis de una forma", D'Art. Revista del Departament d'Historia de l'Arte, 5, 1979, pp. 5-20. 
acanto, todo ello en disposición radial y naciendo del cuerpo superior. Este adquiere forma de casquete semiesférico con gruesos gallones cubiertos por grutescos incisos y con otra argolla en su cúspide de la que pende la lámpara ${ }^{14}$.

Este análisis estético, por lo tanto, coincide con los trabajos documentados de la orfebrería sevillana de mediados del siglo XVI, y que se refrenda si tenemos en cuenta la pareja de marcas que están estampadas en la orilla del plato. En concreto, presenta la marca de la ciudad de Sevilla, la Giralda, acompañada de otro punzón, claramente del marcador o contraste pues, como era costumbre en la época, aparecen juntas, siendo esta la propia de Hernando de Ballesteros el Viejo (Figura 4). Con respecto a la primera, reproduce la que fue denominada como tercera variante de la marca de Sevilla por el profesor Cruz Valdovinos ${ }^{15}$. Recoge la torre compuesta por tres cuerpos, el intermedio con rayas cruzadas imitando los paños de sebka, el cuerpo inferior con huecos donde son muy visibles unas campanas, y la palabra "SEVILA" en su base, en caracteres latinos, muy centrada respecto a la torre. Bien es cierto que en este caso la marca está algo frustra en su estampación y no se aprecian las aludidas tracerías islámicas de la torre almohade, pero no hay duda de su identificación si la comparamos con la que muestran otras muchas piezas de este periodo. Hasta el momento, además de la lámpara ursaonense, son nueve las piezas conocidas con esta marca: la cruz parroquial de Santa María de Sanlúcar la Mayor, un cáliz de la basílica de Santa María de Arcos de la Frontera, la cruz de altar del convento agustino de Nuestra Señora de Gracia de Ávila, la cruz de cristal de la catedral de Sevilla, la custodia de asiento de la catedral de Santo Domingo en la República Dominicana, las crismeras de la parroquia de Palomares del Río, el cáliz y portapaz de la parroquia de San Juan de Marchena, y el hostiario de la parroquia de Santa Catalina de Jerez de los Caballeros ${ }^{16}$. Y precisamente con estas dos últimas obras comparte la lámpara del Santo Sepulcro el mismo punzón de marcador, pues junto a la Giralda, en el portapaz de Marchena y en el píxide de Jerez, aparece también el punzón de "FER (la E y R fusionadas) ${ }^{\mathrm{DO}}$ ballesta", una marca nominativa utilizada por el platero Hernando de Ballesteros el Viejo también para punzonar sus

${ }^{14}$ En la actualidad también presenta un añadido moderno intermedio, a base de otras tres cadenas que sujetan un aro circular para colocar un plato de cristal sobre el que se pone una vela.

${ }^{15}$ CRUZ VALDOVINOS, José Manuel: Cinco siglos..., op. cit., pp. LXVIII-LXIX.

${ }^{16}$ SANZ SERRANO, María Jesús: La orfebrería sevillana..., T. II, op. cit., p. 162; CRUZ VALDOVINOS, José Manuel: Cinco siglos..., op. cit., pp. 28-25, 38-40 y 41-42; SANZ SERRANO, María Jesús: "Noticias sobre el platero Marcos Beltrán", Archivo Hispalense, 252, 2000, pp. 175-192; y MARTÍN SÁNCHEZ, Lorenzo y GUTIÉRREZ HERNÁNDEZ, Fernando: "Cruz de altar", en Testigos. Las Edades del Hombre. Ávila, 2004, pp. 323-324. 
propias creaciones ${ }^{17}$. Pero lo difícil en el caso de este orfebre toledano, afincado en Sevilla hacia 1540 y que llegó a ser platero catedralicio entre 1551 y 1579, es saber cuándo fue marcador de plata de la ciudad de Sevilla. Parece que la clave está en un documento que permite entrever cierto protagonismo de Ballesteros en la organización y gestión del gremio de San Eloy. En una demanda presentada por los plateros contra la ciudad de Sevilla el 5 de noviembre de 1549, argumentando su rechazo a la obligación de contribuir con treinta y cinco ducados anuales a la fiesta del Corpus en vez de costear un carro como era la costumbre, esta solicitud aparece encabezada por Alonso Hernández de Rojas, Hernando de Ballesteros y Juan Bautista, lo que hace presuponer que fuesen padre mayor y veedores de plata y oro respectivamente ${ }^{18}$. Un oficio de veedor de plata que, en el caso sevillano, se puede vincular con el de marcador de plata. Desde la Pragmática de los Reyes Católicos del 12 de abril de 1488, el fiel de pesos y pesas de latón era asimismo marcador de la plata en todo el reino de Castilla ${ }^{19}$. En Sevilla, además, ambos cargos recaían durante el siglo XVI en el veedor de plata del gremio de los plateros, por lo que, si consideramos que Hernando de Ballesteros el Viejo ocupaba este cargo en 1549, según se desprende de la referida demanda, tendría también las facultades de marcar la plata ${ }^{20}$. Además, teniendo en cuenta que estos cargos eran anuales, y sin que exista ninguna otra constancia documental que amplíe cronológicamente su vinculación con dicho cargo de veedor, Ballesteros el Viejo debió actuar como marcador precisamente en dicho año, estampando su marca como tal en el portapaz de Marchena, el hostiario de Jerez y en esta lámpara de Osuna. Una datación que se ajusta perfectamente a su referido estilo, así como al periodo en el que fueron adquiridos los bienes muebles de esta iglesia del Santo Sepulcro por don Juan Téllez Girón, concretamente como referimos en un principio entre 1545 y 1555.

Desgraciadamente no contamos con el tercer punzón que, según estaba regulado por las ordenanzas de los plateros sevillanos de 1540, debían presentar estas piezas y que se correspondería con el del artista que las fabricó ${ }^{21}$. No obstante, es relativamente frecuente encontrarnos esta situación en obras labradas en estos

${ }^{17}$ SANTOS MÁRQUEZ, Antonio Joaquín: Los Ballesteros, una familia de plateros en la Sevilla del quinientos. Sevilla, 2007, pp. 52-55.

${ }^{18}$ CRUZ VALDOVINOS, José Manuel: Cinco siglos..., op. cit., p. 356.

19 Ibidem, p. LVIII.

${ }^{20}$ SANZ SERRANO, María Jesús: El gremio de plateros sevillano. 1344-1867. Sevilla, 1991, p. 39; y CRUZ VALDOVINOS, José Manuel: Cinco siglos..., op. cit., p. LXXII. Hay que tener en cuenta que el oficio de marcador de plata y de fiel de pesos y pesas de latón no fue separado de manera definitiva hasta 1641, cuando este último puesto pasó a ser exclusivo de los plateros sin la intervención del cabildo municipal en su elección. CRUZ VALDOVINOS, José Manuel: Cinco siglos..., op. cit., p. XCVI.

${ }^{21}$ SANZ SERRANO, María Jesús: El gremio de plateros..., op. cit., p. 37. 
años del quinientos. Concretamente hay varias piezas con la misma marca de la ciudad y los punzones de diferentes marcadores pero sin el sello del autor, como sucede por ejemplo en la custodia de la catedral de Santo Domingo, la cruz de cristal de la catedral de Sevilla, el cáliz de Arcos de la Frontera o la cruz parroquial de Sanlúcar la Mayor. En todas estas piezas la marca de contraste, a excepción de la custodia de Santo Domingo, es la de "HERN/ANDO", mientras que junto a la referida de Ballesteros siempre aparece el autor, como sucede en el hostiario de Jerez atribuido a Juan Ruiz el Vandalino y en el portapaz de Marchena de Marcos Beltrán ${ }^{22}$. Quizás aquí en esta lámpara no aparezca la marca de autoría al tratarse de una posible obra del propio Ballesteros, cuestión que tampoco podría extrañarnos si tenemos en cuenta que gran parte del patrimonio adquirido por don Juan Téllez Girón para este recinto procedía de los artistas más reputados de la ciudad, a lo que habría que añadir que la calidad de la pieza tampoco desmerece a la consabida creatividad del platero ${ }^{23}$. Una hipótesis que solo queda en una suposición, pues ante la falta de una documentación que ratifique o desmienta su posible paternidad, y siguiendo un criterio lógico en el análisis de los punzones, la obra debe quedar aún en el anonimato.

Fecha de recepción: 28 de octubre de 2018

Fecha de aceptación: 5 de febrero de 2019

${ }^{22}$ ESTERAS MARTÍN, Cristina: La plata en Jerez de los Caballeros. Badajoz, 1984, pp. 3-6; y SANZ SERRANO, María Jesús: "Noticias sobre el platero Marcos Beltrán", op. cit., pp. 175-192.

${ }^{23}$ Sobre la creatividad de este platero consultar SANTOS MÁRQUEZ, Antonio Joaquín: Los Ballesteros..., op. cit., pp. 93-116. 


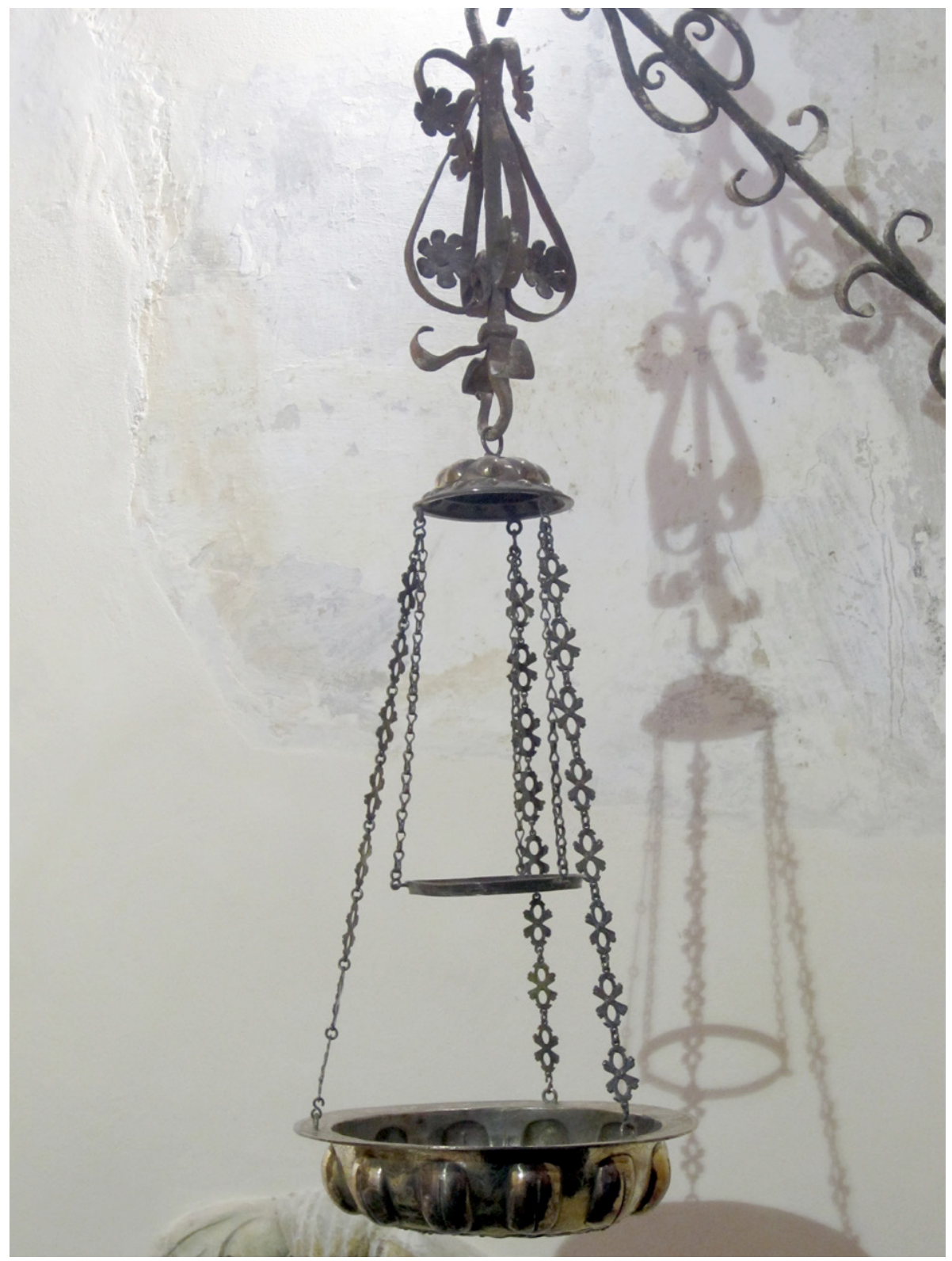

Figura 1. Anónimo, lámpara, 1549, sagrario de la iglesia del Santo Sepulcro de Osuna. Foto: José Roda Peña. 


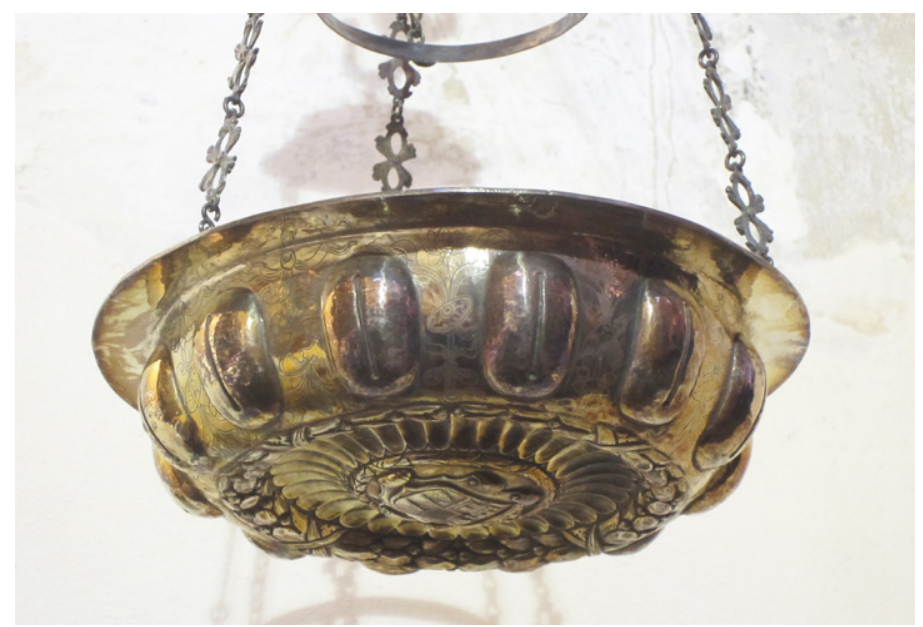

Figura 2. Anónimo, plato de la lámpara, 1549, sagrario de la iglesia del Santo Sepulcro de Osuna. Foto: José Roda Peña.

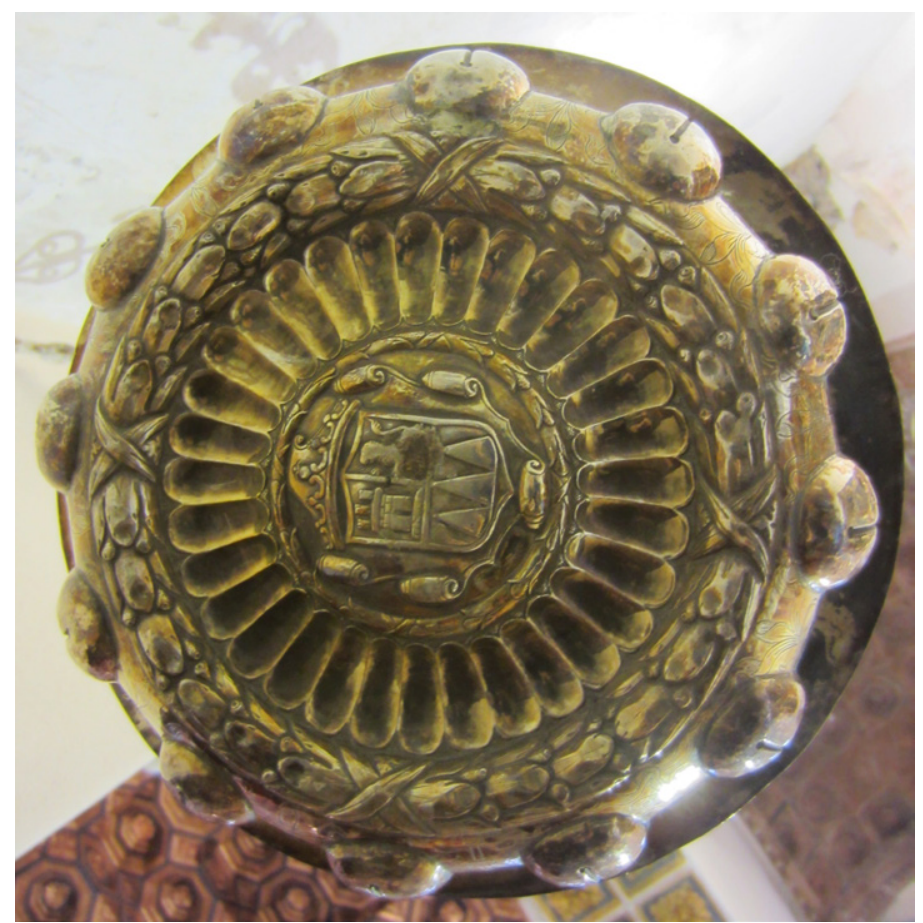

Figura 3. Anónimo, detalle del plato de la lámpara, 1549, sagrario de la iglesia del Santo Sepulcro de Osuna. Foto: José Roda Peña. 


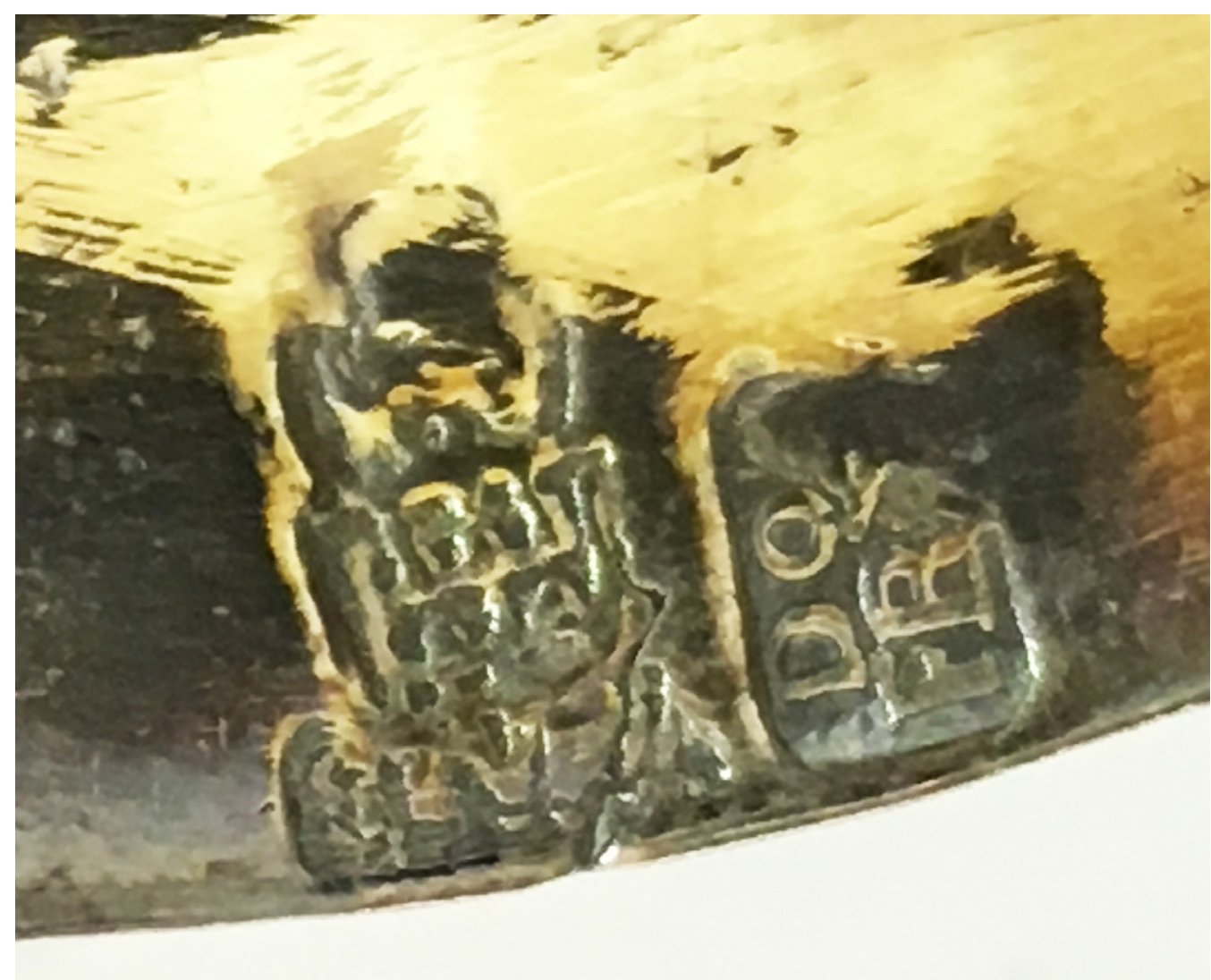

Figura 4. Anónimo, punzones de la ciudad de Sevilla y de Hernando de Ballesteros el Viejo (contraste) ubicados en el anverso de la orilla de la lámpara, 1549, sagrario de la iglesia del Santo Sepulcro de Osuna. Foto: Antonio J. Santos Márquez. 